\title{
ALPORT'S SYNDROME: A CASE REPORT
}

Vishal Yadav, Abhishek Singhai, Dolly Joseph, Rajesh Kumar Jha, Padmanabh Sharma

1. Post Graduate Student, Department of Medicine, Sri Aurobindo Medical College \& PG Institute, Indore, India.

2. Assistant Professor, Department of Medicine, Sri Aurobindo Medical College \& PG Institute, Indore, India.

3. Associate Professor, Department of Medicine, Sri Aurobindo Medical College \& PG Institute, Indore, India.

4. Professor \& Head, Department of Medicine, Sri Aurobindo Medical College \& PG Institute, Indore, India.

5. Post Graduate Student, Department of Medicine, Sri Aurobindo Medical College \& PG Institute, Indore, India.

\section{CORRESPONDING AUTHOR}

Dr. Vishal Yadav, Department Of Medicine, Sri Aurobindo Medical College \& PG Institute, Indore, India E-mail: vishal_23882@indiatimes.com Ph: 00919893241111

ABSTRACT: Alport's syndrome is considered to be a widespread disorder of basement membrane, clinically characterised by haematuric nephritis, sensorineural deafness and ocular manifestations. Here we report a case of Alport's syndrome with all the characteristic features.

KEY-WORDS: Alport's syndrome, Haematuric nephritis, Sensorineural deafness

INTRODUCTION: Alport's syndrome is an inherited progressive renal disease that is accompanied by sensorineural hearing loss and ocular abnormalities that affects 1 in 50,000 live births.(1,2) It is a primary basement membrane disorder arising from mutations in genes encoding several members of the type IV collagen protein family. The disease is genetically heterogeneous, existing in X-linked, autosomal recessive, and autosomal dominant forms. Eighty percent of the disease is X-linked, $15 \%$ autosomal recessive, and $5 \%$ autosomal dominant. The most common, $\mathrm{X}$-linked form arises from mutations in COL4A5, the gene encoding the alpha-5 chain of type IV collagen. $(3,4)$

CASE HISTORY: A 21 year old male presented with bilateral progressive diminution of vision from last 1 year, progressive hearing loss from last 6 months, and loss of appetite from last 6 months, and shortness of breath from last one month. Patient also had swelling over face from last 7 days. Patient had progressive renal illness since 7 years of his age managed conservatively for that. He had intermittent episodes of haematuric since last 4 years.

His only elder brother had died of chronic renal disease at the age of sixteen, he was on maintenance hemodialysis. There was no other similar illness in the family.

On examination, patient had tachycardia (pulse 100/minute), hypertensive (BP $170 / 100 \mathrm{mmHg}$ ) and respiratory examination revealed bilateral coarse crackles in lower lung fields. Slit lamp examination of eyes revealed anterior lenticonus in right eye and pseudophakia in left eye after cataract surgery.

His investigations showed $\mathrm{Hb} 3.8 \mathrm{gm} / \mathrm{dl}, \mathrm{WBC}$ count $10000 / \mathrm{mm}^{3}$, increased blood urea $(230 \mathrm{mg} / \mathrm{dl})$ and serum creatinine $(15.60 \mathrm{mg} / \mathrm{dl})$, electrolytes were in normal limits. Urine output for 24 hours was around $1000 \mathrm{ml} /$ day. Renal ultrasound showed bilateral small kidneys ( $8.5 \times 3.8 \mathrm{cms}$ - right , $8.5 \times 3.5 \mathrm{cms}$ - left) with grade 2 parenchymal changes( consistent with medical renal disease).Urine examination revealed mild proteinuria. Audiometry revealed 
bilateral severe sensorineural hearing loss for higher frequencies. On renal biopsy, podocyte hypertrophy was seen on light microscopy. No specific immune deposits were detected by immunofluoroscense. On ultrastructural examination, irregular alteration of thick and split glomerular basement membrane segments were observed. On the basis of typical triad of positive family history, sensorineural deafness and medical renal disease diagnosis of Alport's syndrome made. Patient treated with diuretics, antihypertensive, blood transfusion, maintenance hemodialysis and hearing aid.

DISCUSSION: In 1927, Cecil A. Alport described 3 generations of a family with combinations of progressive hereditary nephritis and deafness. Alport also noted that haematuric was the most common presenting symptom, and that males were affected more severely than females.

Abnormality in alpha-5 chain of type IV collagen impairs the integrity of the basement membrane in the glomerulus, cochlea and eye, leading to the clinical manifestations seen in Alport syndrome. The histologic changes seen in the kidney in Alport syndrome include early thinning of the basement membrane and late development of longitudinal splitting of the glomerular basement membrane on electron microscopy, producing a laminated appearance. The clinical manifestations include recurrent episodes of gross haematuric, especially in childhood. This is usually preceded by asymptomatic microhematuria. Early in the course the plasma creatinine and blood pressure are normal, but eventually hypertension, azotemia, and proteinuria develop. End-stage renal disease is usually seen in males between the ages of 16 and 35 , but some families have more indolent disease and develop renal failure in their 40 s or $50 \mathrm{~s}$. Extrarenal manifestations most commonly include eye and ear changes. Sensorineural hearing loss can take place and initially involve the high tones but can eventually affect the ability to hear conversational speech. Eye changes include anterior lenticonus, white or yellow flecking of the perimacular region of the retina, and corneal lesions such as posterior polymorphous dystrophy and recurrent corneal erosions.(5) The diagnosis of Alport syndrome is usually established via a careful family history which reveals renal disease and deafness. However, in $15 \%$ of cases there is no family history and the diagnosis is established via renal biopsy. Subsequently, a diagnosis of Alport syndrome can be confirmed or excluded in the majority of cases by the performance of a renal biopsy with analysis of type IV collagen expression in the kidney.

No definite treatment exists for Alport syndrome. Supportive treatment for Alport syndrome includes ACE inhibitors, which have been used to treat hypertension as well as reduce proteinuria. Cyclosporine has also been used to halt disease progression in those patients with severe proteinuria.(6) In those patients with end-stage renal disease, both dialysis and transplantation are options, however anti-glomerular basement membrane disease can develop in 3-4\% of transplanted patients. ${ }^{(7)}$ Gene therapy for Alport syndrome is being studied. Animal studies are underway to evaluate the delivery of human alpha-5 (IV) chain of GBM in a canine model of X-linked Alport's syndrome.(8)

CONCLUSION: It is important to recognize Alport's syndrome early in the course of the disease. This is facilitated by an integrated approach to diagnosis. Early diagnosis can improve longevity and improve prognosis of Alport's syndrome patients.

\section{REFERENCES:}

1. Alport AC. Hereditary congenital hemorrhagic nephritis. BMJ 1927;1:504-6. 
2. Kashtan CE. Alport syndrome: an inherited disorder of renal, ocular and cochlear basement membranes. Medicine 1999;78:338-60.

3. Feingold J, Bois E, Chompret A, Broyer M, Gubler MC, Grünfeld JP. Genetic heterogenerity of Alport syndrome. Kidney Int 1985;27:672-677.

4. Hudson BG, Tryggvason K, Sundaramoorthy M, Neilson EG. Alport's syndrome,Goodpasture's syndrome and type IV collagen. New Engl J Med 2003; 348:2543-56.

5. Govan AA. Ocular manifestations of Alport's syndrome: a hereditary disorder of basement membranes? Br J Ophthalmol 1983;67:493-503

6. Callis L, Vila A, Carrera M, Nieto J. Long-term effects of cyclosporine A in Alport's syndrome. Kidney Int 1999;55:1051

7. Mazzarella V, Splendiani G, Tozzo C. Renal transplantation in patients with hereditary kidney disease: our experience. Contrib Nephrol 1997;122:203-6

8. Heikkilä P, Tryggvason K, Thorner P. Animal models of Alport syndrome: advancing the prospects for effective human gene therapy. Exp Nephrol 2000;8:1-7

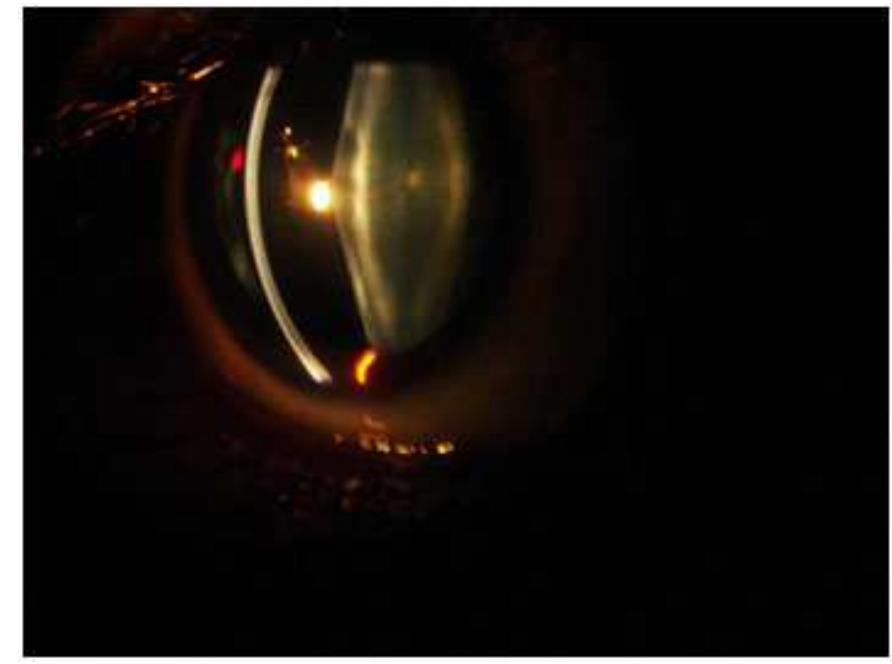

Anterior Lenticonus

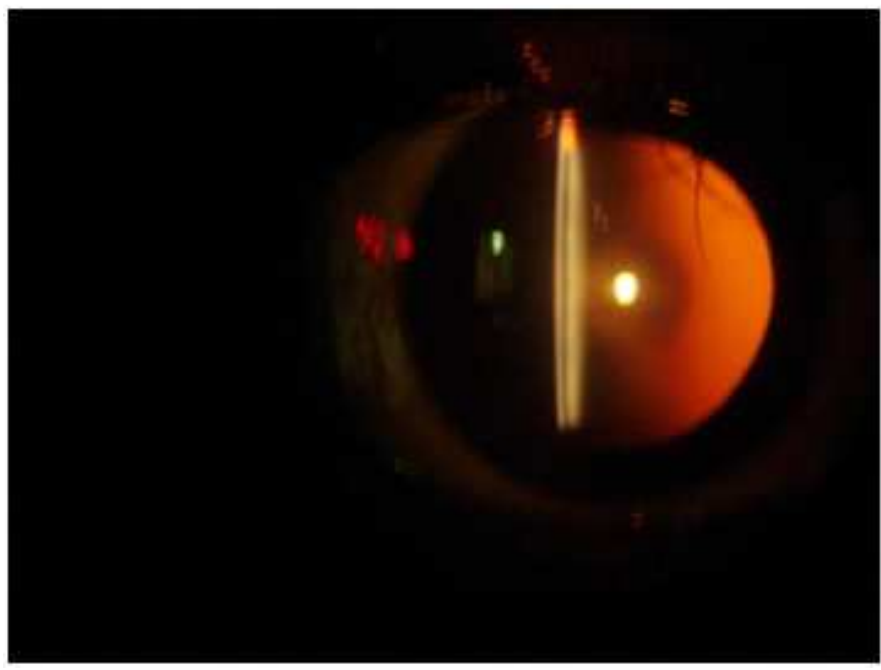

Oildrop arrearance against redglow 